\title{
An assessment of mobile phone-based dissemination of weather and market information in the Upper West Region of Ghana
}

\author{
Prince Maxwell Etwire ${ }^{1}$, Saaka Buah ${ }^{1}$, Mathieu Ouédraogo ${ }^{2^{*}} \mathbb{B}$, Robert Zougmoré2 ${ }^{2}$, Samuel Tetteh Partey ${ }^{2}$, \\ Edward Martey', Sidzabda Djibril Dayamba ${ }^{3}$ and Jules Bayala ${ }^{3}$
}

\begin{abstract}
Background: The rapid growth of mobile phones in Ghana has opened up the possibility of delivering timely and useful weather and market information to farmers at costs lower than traditional agricultural extension services. In this paper, we assess the usefulness, constraints, and factors likely to influence farmers' decisions to patronize mobile phone-based weather and market information.

Methods: We rely on primary data from 310 farmers in the Upper West Region, an understudied part of Ghana. We subject the data to three types of analysis. First, we model farmers' decision to patronize mobile phone-based weather and market information by estimating a binary logit model. Second, we use descriptive statistics and hypothesis testing to analyse the level of usefulness of mobile phone-based weather and market information. We disaggregate the analysis by sex, income status, and age group. Finally, we use qualitative analysis to summarize the constraints associated with the utilization of mobile phone-based weather and market information.
\end{abstract}

Results: We find that contact with agricultural extension agents and farmer-to-farmer extension services significantly influences farmers' decision to patronize mobile phone-based weather and market information. Regardless of sex, income status, and age group, farmers generally rate mobile phone-based weather and market information as very useful. We identify inexact information, complex text messages, information that are too costly to implement, and poor infrastructure as the constraints to the utilization of mobile phone-based weather and market information.

Conclusion: In order to improve the utilization of mobile phone-based weather and market information, disseminators of mobile phone-based information such as Esoko should constantly update and provide client-specific information. Improvements in mobile phone networks and related services will enhance the utilization of mobile phonebased weather and market information.

Keywords: Agricultural extension, Binary logit, Esoko, Ghana, Mobile phone, Weather and market information

\section{Background}

Access to weather and market information has always been a challenge for farmers in developing countries. Access to information is often hindered by factors such as poor infrastructure, illiteracy, financial constraints, and poor communication methods [1]. Lack of weather and

\footnotetext{
*Correspondence: m.ouedraogo@cgiar.org

${ }^{2}$ International Crops Research Institute for the Semi-Arid Tropics (ICRISAT), P. O. Box 320, Bamako, Mali

Full list of author information is available at the end of the article
}

market information can lead to high marketing and production costs [2], low farm productivity, and exploitation by traders [1], who sometimes take advantage of farmers' lack of information by offering to pay very low prices for farm produce [4]. Access to weather and market information enables farmers to properly plan their production, get a good bargain, choose between markets, and take advantage of market opportunities [3]. According to Courtois and Subervie [4], farmers (in the eastern corridor of the Northern Region of Ghana) who subscribe to mobile phone-based price alerts sell their produce at a 
significantly higher price. The price difference is 12.7 and 9.7\% for maize and groundnut, respectively.

As a result of climate change, increasing globalization and commercialization, and changes in consumption patterns, the demand for farm level information appears to be on the increase [2]. To meet this demand, several innovative extension approaches are being implemented in different parts of the world including private or paid extension services, community-wide extension services, farmer group extension services, farmer field schools and training centres, specialized extension services, and more recently, Information and Communication Technology (ICT)-based extension services [3]. In Ghana, the extension approaches being implemented (by both governmental and non-governmental agencies) include training and visit, commodity-specific extension services, farmer field schools, and ICT-based (mobile phone and community radio station) extension services [5].

The Government of Ghana, relying on a work force of public extension agents, operates a conventional system of extension delivery designed to disseminate superior agricultural technologies and practices to farmers. Even though conventional agricultural extension services are the main channels through which agricultural information are usually disseminated to farmers in most developing countries [6], they are often characterized by inadequate personnel and logistics [7], poor targeting and reach, and high cost of information dissemination [2]. Constraints to publicly funded extension in Ghana includes underfunding, late disbursement of funds, understaffing (one agricultural extension agent, AEA, is responsible for 2000-3000 farmers or 66 farmer groups), large operational areas (as a result of dispersed rural settlements), ageing staff, limited opportunities for knowledge upgrading, and few female staff [8]. Hence, the recent introduction of ICT-based extension services, which have the potential of delivering advanced and realtime information, seems appropriate [6].

Compared to conventional extension approaches, it has been shown that ICTs such as mobile phones are a more convenient way to deliver useful and up-to-date weather and market information [1]. For extension providers, mobile phone-based services enable the delivery of content-specific information, extensive creation of awareness, and reduction in the cost of diffusing information manually. Besides, by relying only on conventional approaches, extension providers may not be able to sufficiently meet the increasing demand for information [2]. For extension users, mobile phone-based services are beneficial for reducing transaction, information search, and travel costs. Weather and market information received through mobile phones enable farmers to make informed decisions, negotiate better with traders, choose the best markets, and plan properly for the future [2, 9]. The rapid growth of mobile phones in Ghana has opened up the possibility of delivering weather and market information through mobile phones. About $85 \%$ of the country is under mobile phone network coverage, though the quality of coverage differs from place to place. More than $65 \%$ of rural dwellers have access to mobile phones [5].

Esoko (Esoko Networks Limited) is an information management platform that collects and disseminates information to its subscribers through the mobile phone and website $[1,3,5]$. Subscription fees range from US $\$ 35$ to 1500 per annum [1]. Information provided by the platform includes input and output prices, bids and offers, weather forecast, and tips on good agricultural practices $[1,3,5]$. Subscribers get information either through short message service (SMS) alerts or by placing a call to the platform. Esoko (formerly TradeNet) was formed in Ghana in 2005 [5]. Even though it often partners with not-for-profit organizations and development projects, Esoko is a profit-oriented company with private investors [1]. Esoko collects information through a network of field agents [3] and from credible secondary sources. At the end of 2011, 10,000 farmers were receiving information on 20 commodities across 30 Ghanaian markets [5].

In 2014, the Consultative Group for International Agricultural Research (CGIAR) Program on Climate Change, Agriculture and Food Security (CCAFS) in collaboration with Esoko-Ghana began a project to disseminate mobile phone-based weather and market information to farmers in the Upper West Region of Ghana. Under the partnership, the information that Esoko disseminates to farmers is obtained from the Ministry of Food and Agriculture (MoFA), the Savanna Agricultural Research Institute (SARI) of the Council for Scientific and Industrial Research (CSIR), and the Ghana Meteorological Agency (GMET). The project is being implemented in 10 communities in two districts of the Upper West Region of Ghana. By the end of 2014, about 1000 farmers were accessing mobile phone-based market and weather information as a result of the CCAFS-Esoko intervention.

In this paper, we assess the usefulness, constraints, and factors likely to influence farmers' decisions to patronize mobile phone-based weather and market information. The literature on mobile phone-based extension is still developing as the approach is only a recent addition to the extension toolkit $[2,3]$. A review of the emerging literature shows that only a few studies apply economic methods to analyse mobile phone-based extension services [e.g. 4, 6, 7, 9, 18, 19]. In this paper, we apply economic models to study mobile phone-based extension in Ghana. We use data from the Upper West Region, an understudied part of the country. We also differentiate farmer-to-farmer extension from formal extension 
services in order to determine which type of extension service has a larger effect on the probability of patronizing mobile phone-based weather and market information. We find that the former has a larger effect. Regardless of sex, income status, and age group, farmers generally rate mobile phone-based weather and market information as very useful. We identify inaccurate information, technical text messages, information too costly to implement, and poor infrastructure as the constraints to the utilization of mobile phone-based weather and market information.

The rest of the paper proceeds as follows: in the next section, we present the methodology of the study by describing the research area, data, and methods of analysis. We then present and discuss the empirical results, and close with our conclusions.

\section{Methods}

\section{Study area}

The Jirapa and Lawra districts of the Upper West Region of Ghana formed our study area. The Upper West Region is located at the north-western part of Ghana (Fig. 1).
The Jirapa District is situated between latitudes $10.25^{\circ}$ and $11.00^{\circ}$ north, and longitudes $2.25^{\circ}$ and $2.40^{\circ}$ west, covering an area of $1188.6 \mathrm{~km}^{2}$ [10]. The Lawra District is located between latitudes $10.35^{\circ}$ and $10.40^{\circ}$ north and longitudes $2.50^{\circ}$ and $2.53^{\circ}$ west and covers $527.37 \mathrm{~km}^{2}$ [11]. Average annual temperature ranges between 27 and $36^{\circ} \mathrm{C}$. A single rainy season is experienced between April and October with annual rainfall amounting to 1000 $1100 \mathrm{~mm}$. Rainfall is erratic. The agroecology of the study area is Guinea savannah woodland. Mobile phone telecommunication networks operating in the area include Mobile Telephone Networks (MTN), Vodafone, Airtel, and Tigo. Mobile phone-based money transactions are common in the study area $[10,11]$.

\section{Data}

Our analyses are based solely on primary data collected through farmer interviews and focus group discussions. A semi-structured questionnaire for the farmer interviews and a guide for the focus group discussions were developed, pre-tested, and administered (in the local dialect) by trained enumerators. We collected data on sex,

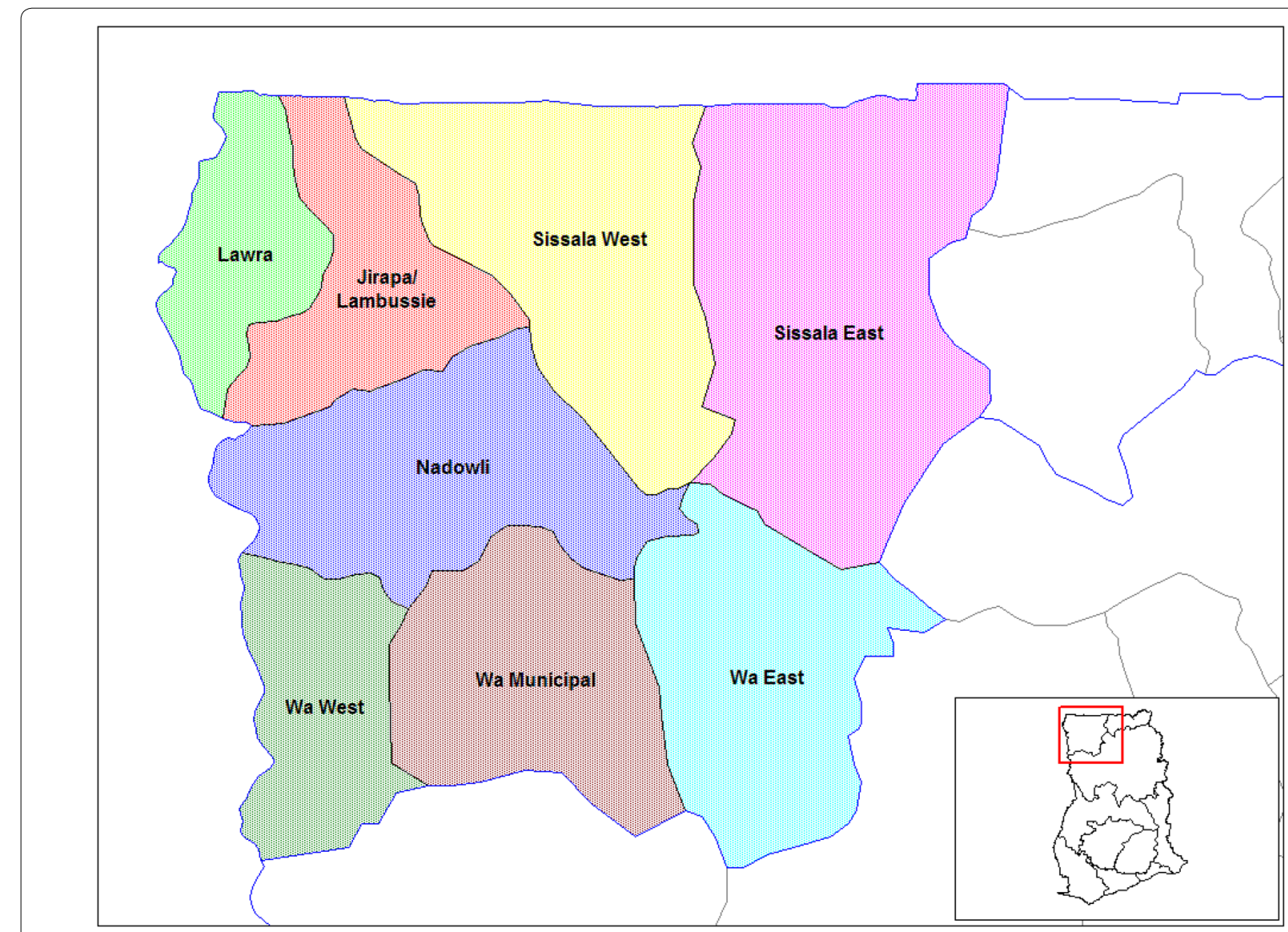

Fig. 1 Map of Ghana showing the study area 
educational attainment, age, marital status, farm size, access to extension, income (crop, livestock, and offfarm), utilization of mobile phone-based weather and market information, rating of usefulness and constraints to the utilization of mobile phone-based weather and market information. The level of usefulness was measured on a 5-point Likert scale, i.e. not useful at all, not useful, indifferent, useful, and very useful.

Our hypothesized population was farmers who participated in (were exposed to) the CCAFS-Esoko project (mobile phone-based extension services). Hence, we purposively sampled the Upper West Region of Ghana, specifically the Jirapa and Lawra districts where the project is being implemented. We selected all the project communities ( 5 in each district). Our target was to randomly interview 160 farmers in each district (i.e. 32 farmers per community). For Lawra, however, only 150 farmers were successfully enumerated. Thus, a total of 310 farmers were interviewed from the 10 communities. One focus group discussion was held in each community. The survey was implemented between February and March 2015.

\section{Methods of analysis}

We subject our data to three types of analysis. First, we model farmers' decision to patronize mobile phonebased weather and market information as a binary choice (farmers can either choose to subscribe to Esoko or otherwise). Consequently, we estimate a binary logit model. The motivation and derivation of the binary logit model can be found in several econometric textbooks [e.g. 1215]. We empirically estimate the equation;

$$
\begin{aligned}
\operatorname{Pr}(\text { Patronize }=1)= & F\left(\beta_{0}+\beta_{1}\right. \text { AEA contact } \\
& \left.+\beta_{2} \text { Farmer_to_farmer }\right)
\end{aligned}
$$

where $\operatorname{Pr}($ Patronize $=1)$ is the probability that a farmer will patronize mobile phone-based weather and market information, $F(z)=\frac{e^{z}}{\left(1+e^{z}\right)}$ is the cumulative logistic distribution, and AEA stands for agricultural extension agent as earlier indicated. Our data show that $71.6 \%$ of the sampled farmers used mobile phones to access weather and market information from Esoko. Descriptive statistics of the independent variables are presented in Additional file 1.

Second, we use descriptive statistics and hypothesis testing to analyse the level of usefulness of mobile phonebased weather and market information. We disaggregate the analysis by three categorizations. We group farmer ratings on the basis of sex, age group, and income status. Based on sex, we group farmers as either males (84.1\%) or females (15.9\%). Based on age, we categorize farmers as either young or old. The young category consists of farmers below the age of 50 years (45.5\%). Based on income, we categorize farmers as either poor or non-poor. Poor farmers are those with annual income of less than $\mathrm{GH} \$ 1,460^{1}$ (72.7\%).

The ratings of usefulness, presented in the form of graphs, were done by farmers who reported patronizing Esoko's mobile phone-based weather and market information services. Specifically, we plot histograms of the ratings whilst enabling, in the background, curves for the normal distribution of the ratings. In order to examine whether the ratings vary among different categories of farmers, we subject them to the Wilcoxon-MannWhitney test [17]. We also subject the ratings to the Kruskal-Wallis test which is a more general form of the Wilcoxon-Mann-Whitney test [15].

Finally, we qualitatively analyse the constraints to the utilization of mobile phone-based weather and market information disseminated by Esoko. Since we did not pre-code the constraints, we simply summarize and discuss the responses.

\section{Results and discussion \\ Factors influencing utilization of mobile phone-based weather and market information}

The parameter estimates of our binary logit model are presented in Table 1. Results of the log-likelihood test show that a model with covariates is to be preferred to a model with only an intercept. Based on the Count $\mathrm{R}^{2}$, our covariates jointly determine $78.1 \%$ of farmers' decision to patronize mobile phone-based weather and market information. Since the parameter estimates of the binary logit are not directly useful in explaining the nonlinear relationships between the dependent and independent variables [13], we report and discuss the marginal effects (Table 1). The probability of farmers patronizing mobile phone-based weather and market information varies directly with access to agricultural extension.

Compared with AEA contact, farmer-to-farmer extension has a larger effect on the probability of patronizing mobile phone-based weather and market information (Table 1). AEAs serve as a traditional link between agriculturalists and innovators. They are often partnered by other institutions and development projects to disseminate and monitor the adoption of agricultural innovation. AEAs are helpful in explaining complex terminologies, translating information from English to the local dialect or even assisting in the operation of a mobile phone [9]. Hence, farmers who have contact with AEAs are more likely to access mobile phone-based weather and market information. This notwithstanding, the probability of farmers patronizing mobile phone-based weather and market information is higher if they are introduced

\footnotetext{
${ }^{1}$ This translates to less than US\$1.25 per day. The 2014 end-period GHd/ US\$ exchange rate is $3.2[16]$.
} 
Table 1 Parameter estimates and marginal effects of the binary logit model

\begin{tabular}{lll}
\hline Variable & Coefficient & Marginal effect \\
\hline $\begin{array}{l}\text { Contact with agricultural } \\
\text { extension agent (AEA) }\end{array}$ & $0.820^{* * *}(0.302)$ & $0.1426^{* * *}(0.0551)$ \\
Farmer-to-farmer & $1.868^{* * *}(0.287)$ & $0.3602^{* * *}(0.0537)$ \\
Constant & $-0.635^{* *}(0.282)$ & \\
\hline
\end{tabular}

**, *** Signify significance levels at 5 and 1 per cent, respectively. Number of observations $=310$; Wald $\mathrm{Chi}^{2}(2)=49.62$; Prob $>\mathrm{Chi}^{2}=0.000$; Count

$\mathrm{R}^{2}=0.781$; log pseudo-likelihood $=-150.89$. Standard errors are in parentheses

to the information platform (Esoko) by fellow farmers as opposed to AEAs. Similarities in socioeconomic conditions and development of trust and personal relationships over time could be making farmer-to-farmer extension more effective than formal extension. Recommendations from fellow farmers are more likely to carry extra weight since such recommendations are usually based on real-life experience (comparable socioeconomic circumstances); thus, adopting farmers are almost certain to get similar results as recommending farmers. Anoop et al. [9] also report a positive relationship between contact with extension agents and adoption of ICT-based market information services in India.

In order to check the reliability of our estimates, we subject our analysis to a number of diagnostic and robustness checks. First, we check for correlation between our independent variables. Results of the pairwise correlation test (Additional file 1) show that our covariates are weakly correlated and hence multicollinearity is not likely to be a serious problem. Second, we rely on the Huber/White/sandwich estimator to generate heteroscedasticity-robust standard errors. In addition, we estimate a number of comparable models (Additional file 1). Our preferred or parsimonious model is model M1. We prefer M1 because of its good (diagnostic results and low BIC and penalized AIC values) fit. A model with a smaller AIC or BIC value is to be preferred to one with a higher value since small values signify that only a small amount of information is lost by using the selected model to represent the true model [20]. Model M2 is similar to M1 except that we estimate it using the bootstrap technique with 400 replications. Bootstrapping is an estimation technique that resamples (with replacements) the sample or stored data several times in order to generate an inferential statistic $[14,15]$. Using the same variables, we estimate a probit model and present the results as M3. Different assumptions are made about the distribution of the error term for probit and logit models. Whereas logit models assume a logistic distribution, a normal distribution is assumed for probit models $[13,14]$. We control for additional covariates in models M4-M6. In M4, we control for sex and age. In addition to sex and age, we control for educational and marital status in M5 (we measure educational attainment and marital status as categorical variables with 4 options each). M6 is similar to M5 except we reconstruct educational and marital status as dummy variables. We did also test the effects of some other policy variables (e.g. farm size) and further explored the possibility of nonlinear effects (e.g. square of age). Generally, we find that the marginal effects of AEA contact and farmer-to-farmer extension do not change much between models.

\section{The usefulness of mobile phone-based weather and market information}

Figure 2 shows farmers' rating of the level of usefulness of weather and market information obtained from the Esoko platform disaggregated by sex, income status, and age group. We also show the ratings by location in Additional file 2. Overall, we find that farmers rate the information received from the Esoko platform as very useful. The options "not useful" and "not useful at all" were not selected by any of the respondents. Tables 2 and 3 present the results of the Wilcoxon-Mann-Whitney and Kruskal-Wallis tests. Based on the $95 \%$ confidence interval, we do not find evidence to reject the null hypothesis that the ratings are similar across sex, income status, and age group. The only exception is when we restrict the analysis to observations from the Lawra District in which case the ratings of males differ from females.

The ratings suggest that mobile phone-based dissemination of information is a useful alternative to the conventional agent-based extension services. The relatively high costs associated with agent-based extension delivery, inability to update information between extension visits, and supply-driven extension services are some constraints that could be addressed by adopting mobile phone-based dissemination of information. According to Mawazo [1], farmers with adequate access to weather and market information can improve their productivity and profits through proper planning of their production activities and making of informed marketing decisions. Additionally, weather forecasts can be useful in assisting farmers to better adapt to climate change and variability. Mittal [2] reported that more than $90 \%$ of farmers in India find weather and market information delivered through mobile phones as useful. In Tanzania, 96.5\% of farmers report that mobile phones are a useful means for obtaining livestock information [21].

\section{Constraints to the utilization of mobile phone-based weather and market information}

Even though farmers rate the weather and market information obtained from the Esoko platform as very useful, 

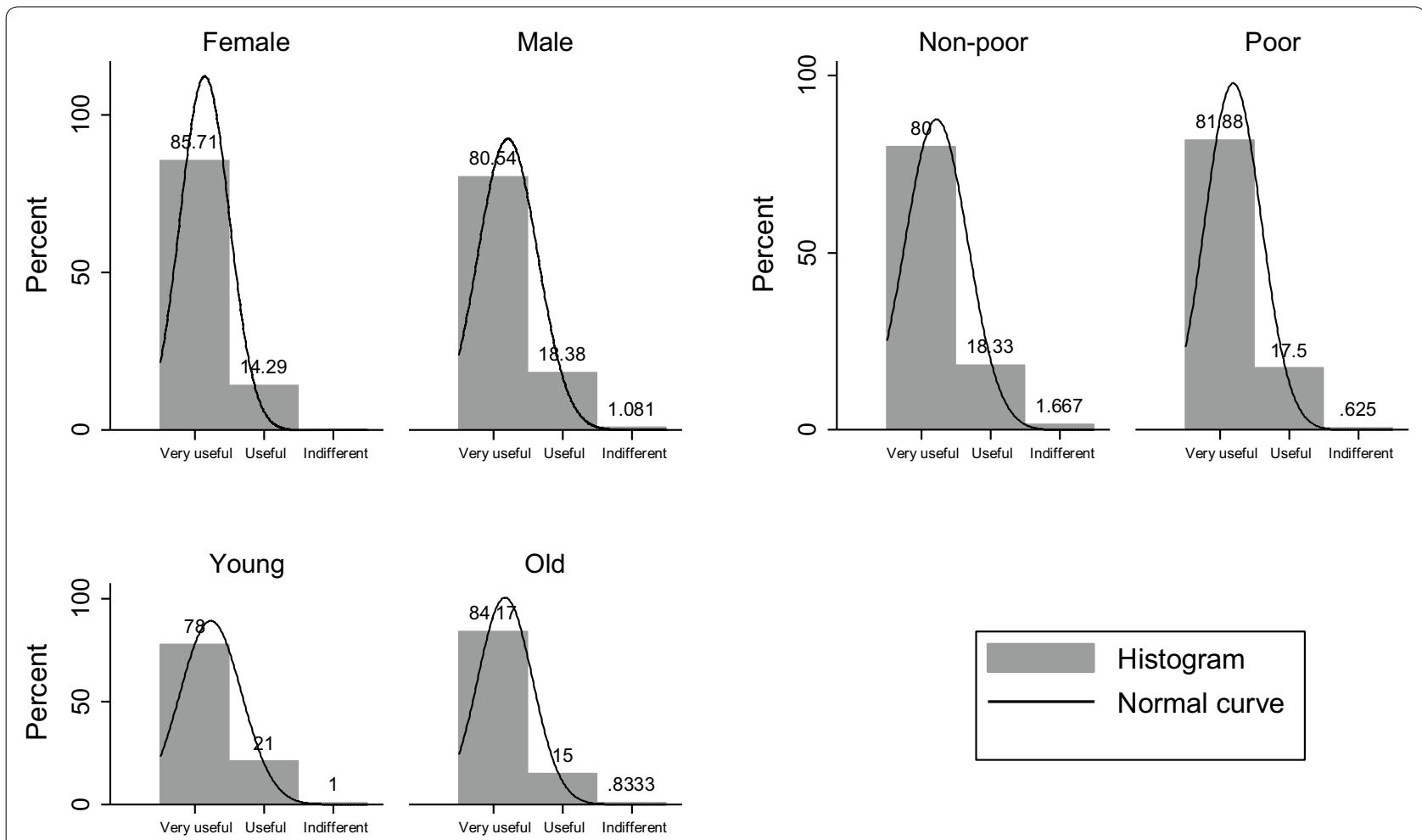

Fig. 2 Ratings of the usefulness of mobile phone-based weather and market information disaggregated by sex, income status, and age group

Table 2 Two-sample Wilcoxon rank-sum (Mann-Whitney) test

\begin{tabular}{|c|c|c|c|c|c|}
\hline Category & Rank sum & Category & Rank sum & Category & Rank sum \\
\hline \multicolumn{6}{|c|}{ Total sample } \\
\hline Female & 3695 & Non-poor & 6728.5 & Young & $11,418.5$ \\
\hline Male & 20,615 & Poor & $17,581.5$ & Old & $12,891.5$ \\
\hline z & -0.74 & z & 0.347 & z & 1.161 \\
\hline Prob $>|z|$ & 0.4594 & Prob > |z| & 0.7286 & Prob $>|z|$ & 0.2456 \\
\hline \multicolumn{6}{|c|}{ Lawra District } \\
\hline Female & 179 & Non-poor & 663.5 & Young & 1317 \\
\hline Male & 2377 & Poor & 1892.5 & Old & 1239 \\
\hline z & 1.158 & z & 0.272 & z & 1.974 \\
\hline Prob $>|z|$ & 0.2468 & Prob > |z| & 0.7857 & Prob $>|z|$ & 0.0484 \\
\hline \multicolumn{6}{|c|}{ Jirapa District } \\
\hline Female & 2189 & Non-poor & 3193 & Young & 5001 \\
\hline Male & 8986 & Poor & 7982 & Old & 6174 \\
\hline z & -1.015 & z & 0.29 & z & -0.146 \\
\hline Prob $>|z|$ & 0.31 & Prob $>|z|$ & 0.7721 & Prob $>|z|$ & 0.8838 \\
\hline
\end{tabular}

$H_{0}$ : ratings (of the level of usefulness of mobile phone-based weather and market information) within a category are similar

they still face some constraints in accessing and utilizing the information. There are instances where the information provided by Esoko either failed (e.g. weather forecast) or was no longer accurate (e.g. output prices). In addition, text messages are sometimes not self-explanatory or elaborate; hence, some farmers (especially farmers who are not literate) are unable to process and therefore utilize some of the information provided through SMS.

Information obtained from Esoko may not be utilized if farmers are of the view that the information is expensive to implement, or not cost-effective. For example, farmers may decide not to access markets with good output prices if they think the cost of accessing those markets is not cost-effective.

Due to poor infrastructure (e.g. poor rural mobile phone networks, busy or limited networks, and lack of electricity to charge mobile phones), phone calls are sometimes faint or lacking voice clarity whilst timebound SMS from Esoko may be received late, thereby rendering them un-implementable.

In Tanzania, constraints to the utilization of mobile phone-based extension services include high cost of operating a mobile phone, poor network coverage, and lack of electricity [21]. Technical nature of information provided, irrelevant content, unreliability, and high cost of accessing information are some constraints to the utilization of mobile phone-based extension services observed in India [9]. In the Oyo State of Nigeria, high costs, service failure, unstable electricity, and illiteracy 
Table 3 Kruskal-Wallis equality-of-populations rank test

\begin{tabular}{|c|c|c|c|c|c|}
\hline Category & Rank sum & Category & Rank sum & Category & Rank sum \\
\hline \multicolumn{6}{|l|}{ Total sample } \\
\hline Female & 3695 & Non-poor & 6728.5 & Young & $11,418.5$ \\
\hline Male & 20,615 & Poor & $17,581.5$ & Old & $12,891.5$ \\
\hline $\mathrm{Chi}^{2}(1)$ & 0.25 & $\operatorname{Chi}^{2}(1)$ & 0.055 & $\mathrm{Chi}^{2}(1)$ & 0.614 \\
\hline Prob $>\mathrm{Chi}^{2}$ & 0.6174 & Prob $>\mathrm{Chi}^{2}$ & 0.8148 & Prob $>\mathrm{Chi}^{2}$ & 0.4331 \\
\hline Chi ${ }^{2}$ with ties (1) & 0.547 & $\mathrm{Chi}^{2}$ with ties (1) & 0.12 & $\mathrm{Chi}^{2}$ with ties (1) & 1.348 \\
\hline Prob $>\mathrm{Chi}^{2}$ & 0.4594 & Prob > Chi ${ }^{2}$ & 0.7287 & Prob $>\mathrm{Chi}^{2}$ & 0.2456 \\
\hline \multicolumn{6}{|l|}{ Lawra district } \\
\hline Female & 179 & Non-poor & 663.5 & Young & 1317 \\
\hline Male & 2377 & Poor & 1892.5 & Old & 1239 \\
\hline $\operatorname{Chi}^{2}(1)$ & 0.762 & $\operatorname{Chi}^{2}(1)$ & 0.042 & $\operatorname{Chi}^{2}(1)$ & 2.212 \\
\hline Prob $>\mathrm{Chi}^{2}$ & 0.3828 & Prob $>\mathrm{Chi}^{2}$ & 0.8377 & Prob $>\mathrm{Chi}^{2}$ & 0.137 \\
\hline $\mathrm{Chi}^{2}$ with ties (1) & 1.342 & $\mathrm{Chi}^{2}$ with ties (1) & 0.074 & $\mathrm{Chi}^{2}$ with ties (1) & 3.895 \\
\hline Prob $>\mathrm{Chi}^{2}$ & 0.2468 & Prob $>\mathrm{Chi}^{2}$ & 0.7857 & Prob $>\mathrm{Chi}^{2}$ & 0.0484 \\
\hline \multicolumn{6}{|l|}{ Jirapa district } \\
\hline Young & 1317 & Female & 2189 & Non-poor & 3193 \\
\hline Old & 1239 & Male & 8986 & Poor & 7982 \\
\hline $\mathrm{Chi}^{2}(1)$ & 2.212 & $\operatorname{Chi}^{2}(1)$ & 0.404 & $\mathrm{Chi}^{2}(1)$ & 0.033 \\
\hline Prob $>\mathrm{Chi}^{2}$ & 0.137 & Prob $>\mathrm{Chi}^{2}$ & 0.5248 & Prob $>\mathrm{Chi}^{2}$ & 0.856 \\
\hline $\mathrm{Chi}^{2}$ with ties (1) & 3.895 & $\mathrm{Chi}^{2}$ with ties (1) & 1.031 & $\mathrm{Chi}^{2}$ with ties (1) & 0.084 \\
\hline Prob $>\mathrm{Chi}^{2}$ & 0.0484 & Prob $>\mathrm{Chi}^{2}$ & 0.31 & Prob $>\mathrm{Chi}^{2}$ & 0.7721 \\
\hline
\end{tabular}

$H_{0}$ : ratings (of the level of usefulness of mobile phone-based weather and market information) within a category are similar

are some of the constraints to the utilization of ICTbased extension services [7]. Low financial resources, lack of electricity, irrelevant content, and low levels of education were identified as the constraints to the utilization of ICT-based agricultural information in the Gatanga District of Kenya [18].

\section{Summary and conclusions}

Agriculture is increasingly becoming an informationdependent sector requiring a wide range of weather, market, and technical information for effective decisionmaking [6]. In order to eliminate information asymmetry, mobile phone-based services are becoming an important means of providing farmers with weather forecasts and market data $[9,19]$. Lack of market information has traditionally constrained farmers' access to markets [19].

Relying on 310 farmer observations from the Jirapa and Lawra districts of the Upper West Region of Ghana, and employing the Wilcoxon-Mann-Whitney test, descriptive statistics, and the binary logit model, we find that contact with agricultural extension agents and farmer-tofarmer extension services significantly influences farmers' decision to patronize mobile phone-based weather and market information. Regardless of sex, income status, and age group, farmers generally rate weather and market information disseminated through mobile phones as very useful. Poor mobile phone network and complimentary services, inexact information, high cost associated with utilizing some information, and unclear or confusing information are some constraints that hinder the utilization of mobile phone-based weather and market information.

Disseminators of mobile phone-based information such as Esoko should constantly update their information to reflect current conditions. It would be helpful to provide more targeted information. For example, farmers should be given price information of nearby markets. Additionally, it might be useful to provide farmers with information about future markets or price forecasts [2]. Improvement in mobile phone networks and related services will go a long way to enhance the utilization of mobile phone-based weather and market information. Furthermore, agricultural extension projects should consider introducing toll-free calling and messaging services. Alternatively, agricultural projects could provide free mobile phone services for a lead-farmer who would then serve as a nucleus source of information for a host of farmers since farmer-to-farmer extension seems to be effective.

Our study population was constructed to include only those who were exposed to the Esoko platform. A natural extension would be to include observations from a 
control or untreated group. Instead of lumping weather and market information together, a future study could treat weather information distinctly from market information. A future study could also estimate the impact of utilizing weather or market information on variables such as yield and income. Being a cross-sectional study, our paper suffers from all biases associated with crosssectional analysis including unobserved heterogeneity and omitted variable bias which can be addressed with a panel analysis.

\section{Additional files}

\section{Additional file 1.}

Additional file 2.

\section{Abbreviations}

AEA: Agricultural extension agent; AIC: Akaike information criterion; BIC: Bayesian information criterion; CCAFS: Climate Change, Agriculture, and Food Security; CGIAR: Consultative Group for International Agricultural Research; ICT: Information and Communication Technology; SMS: Short message service.

\section{Authors' contributions}

$\mathrm{MO}$ and RZ designed the study. PME, SB, and MO gathered the data, analysed the data, and wrote the manuscript. JB, SDD, STP, and EM revised the document and conducted some additional regression analysis. All authors read, amended the earlier drafts, and approved the final manuscript.

\section{Author details}

${ }^{1}$ Savanna Agricultural Research Institute of the Council for Scientific and Industrial Research (CSIR-SARI), P. O. Box TL 52, Tamale, Ghana. ${ }^{2}$ International Crops Research Institute for the Semi-Arid Tropics (ICRISAT), P. O. Box 320, Bamako, Mali. ${ }^{3}$ World Agroforestry Centre (ICRAF), West and Central Africa Regional Office - Sahel Node, BP: E5118, Bamako, Mali.

\section{Acknowledgements}

This work was funded by the CGIAR Program on Climate Change, Agriculture, and Food Security (CCAFS), which is a strategic partnership of the CGIAR and Future Earth. The CCAFS Program is carried out with funding by CGIAR Fund Donors, the Canadian International Development Agency (CIDA), the Danish International Development Agency (DANIDA), and the European Union (EU); with technical support from the International Fund for Agricultural Development (IFAD). The authors are also grateful to all farmers who participated in the survey. We are thankful to Vincent, Rahinatu, Thomas, Bawa, Maxwell, Peter, Anslem, Mavis, and Hashim for collecting and inputting the primary data

\section{Competing interests}

The authors declare that they have no competing interests.

\section{Availability of supporting data}

The data sets analysed during the current study are available from the corresponding author on request.

\section{Consent for publication}

All authors read, amended the earlier drafts, and approved the final manuscript.

\section{Ethical approval and consent to participate}

We obtained informed consent from each participant of the surveys. Before starting each interview, all interviewees were informed about the context of the study and the anonymous nature of the survey. Permission was sought from participants of interviews. They have all given their consent and have openly and freely answered all questions asked. In addition, this study was conducted in the framework of the Savanna Agricultural Research Institute of the Council for Scientific and Industrial Research (SARI-CSIR) research activities, the mission of the institution being to conduct agricultural research in Northern Ghana with the aim of developing and introducing improved technologies that will enhance overall farm level productivity for improved livelihoods (http://csirsari.org/). Such research involves collecting perceptions of local stakeholders to help direct approaches.

\section{Funding}

This work was funded by the CGIAR Program on Climate Change, Agriculture, and Food Security (CCAFS), which is a strategic partnership of the CGIAR and Future Earth. The CCAFS Program is carried out with funding by CGIAR Fund Donors, the Canadian International Development Agency (CIDA), the Danish International Development Agency (DANIDA), and the European Union (EU), with technical support from the International Fund for Agricultural Development (IFAD).

Received: 15 March 2016 Accepted: 29 December 2016

Published online: 10 April 2017

\section{References}

1. Mawazo MM. Linking rural farmers to markets using ICTs. The Technical Centre for Agricultural and Rural Cooperation (CTA) working paper 15/12. Wageningen, The Netherlands. 2015.

2. Mittal S. Modern ICT for agricultural development and risk management in smallholder agriculture in India. CIMMYT socioeconomics working paper 3, Mexico, DF. 2012.

3. Asenso-Okyere K, Mekonnen DA. The importance of ICTs in the provision of information for improving agricultural productivity and rural incomes in Africa. United Nations Development Programme's Regional Bureau for Africa working paper 2012-015. 2012.

4. Courtois P, Subervie J. Farmer bargaining power and market information services. The Centre for the Study of African Economies conference: Economic development in Africa, 17th-19th March, St Catherine's College, Oxford. 2013.

5. Bell M, Bohn A. Rapid appraisal of the ICT for agricultural extension landscape in Ghana. Discussion paper prepared for the G8 new alliance challenge fund, USAID. 2013.

6. Ali J. Factors affecting the adoption of Information and Communication Technologies (ICTs) for farming decisions. J Agric Food Inf. 2012;13(1):7896. doi:10.1080/10496505.2012.636980.

7. Fawole OP, Olajide BR. Awareness and use of information communication technologies by farmers in Oyo State, Nigeria. J Agric Food Inf. 2012;13(4):326-37. doi:10.1080/10496505.2012.717003.

8. McNamara P, Dale J, Keane J, Ferguson O. Strengthening pluralistic agricultural extension in Ghana. Modernizing extension and advisory services discussion paper, USAID. 2014.

9. Anoop M, Ajjan N, Ashok KR. ICT based market information services in Kerala: determinants and barriers of adoption. Econ Aff. 2015;60(1):117-21.

10. Ghana Statistical Service. Jirapa District analytical report: 2010 population and housing census. Ghana: Accra; 2014.

11. Ghana Statistical Service. Lawra District analytical report: 2010 population and housing census. Ghana: Accra; 2014.

12. Greene WH. Econometric analysis. 7th ed. Upper Saddle River: Prentice Hall; 2012.

13. Long JS, Freese J. Regression models for categorical dependent variables using Stata. 3rd ed. College Station: Stata Press; 2014.

14. Cameron AC, Trivedi PK. Microeconometrics using Stata. Rev ed. College Station: Stata Press; 2010.

15. StataCorp. Stata base reference manual: Release 14. Statistical software. College Station, TX: StataCorp LP. Texas. 2015.

16. Bank of Ghana. Annual report. Ghana: Accra; 2015.

17. Nadim N. The Mann-Whitney U: a test for assessing whether two independent samples come from the same distribution. Tutor Quant Methods Psychol. 2008;4(1):13-20. doi:10.20982/tqmp.04.1.p013.

18. Mwombe SOL, Mugivane Fl, Adolwa IS, Nderitu JH. Evaluation of information and communication technology utilization by small holder banana farmers in Gatanga District, Kenya. J Agric Educ Ext. 2014;20(2):247-61. doi:10.1080/1389224X.2013.788454 
19. Okello JJ, Kirui OK, Njiraini GW, Gitonga ZM. Drivers of use of information and communication technologies by farm households: the case of smallholder farmers in Kenya. J Agric Sci. 2012;4(2):111-24. doi:10.5539/jas.v4n2p111.

20. Burnham KP, Anderson DR. Model selection and multimodel inference: a practical information-theoretical approach. 2nd ed. New York: Springer; 2002.
21. Angello C. Exploring the use of ICTs in learning and disseminating livestock husbandry knowledge to urban and peri-urban communities in Tanzania. Int J Educ Dev Using Inf Commun Technol. 2015;11(2):5-22.
Submit your next manuscript to BioMed Central and we will help you at every step:

- We accept pre-submission inquiries

- Our selector tool helps you to find the most relevant journal

- We provide round the clock customer support

- Convenient online submission

- Thorough peer review

- Inclusion in PubMed and all major indexing services

- Maximum visibility for your research

Submit your manuscript at www.biomedcentral.com/submit 